\title{
Free piston linear generator for low grid power generation
}

\author{
Izzeldin Abdalla ${ }^{1}$, Ezrann Z. Zainal A. ${ }^{2}$, Nur Amalina Ramlan ${ }^{2}$, Firmansyah ${ }^{2}$, Abd. Rashid \\ A. Aziz ${ }^{2, *}$, and Morgan Heikal $^{2}$ \\ ${ }^{1}$ Department of Electrical and Electronic Engineering \\ ${ }^{2}$ Centre for Automotive Research and Electric Mobility \\ ${ }^{122}$ Universiti Teknologi PETRONAS, 32610 Bandar Seri Iskandar, Perak, Malaysia
}

\begin{abstract}
Generating power is of great importance nowadays across the world. However, recently, the world became aware of the climatic changes due to the greenhouse effect caused by $\mathrm{CO}_{2}$ emissions and began seeking solutions to reduce the negative impact on the environment. Besides, the exhaustion of fossil fuels and their environmental impact, make it is crucial to develop clean energy sources, and efforts are focused on developing and improving the efficiency of all energy consuming systems. The tubular permanent magnet linear generators (TPMLGs) are the best candidate for energy converters. Despite being suffering problem of attraction force between permanent magnets and stator teeth, to eliminate such attraction force, ironless-stator could be considered. Thus, they could waive the presence of any magnetic attraction between the moving and stator part. This paper presents the design and analysis of ironless -cored TPMLG for low grid power generation. The main advantages of this generator are the low cogging force and high efficiency. Therefore, the magnetic field computation of the proposed generator has been performed by applying a magnetic vector potential and utilizing a 2-D finite element analysis (FEA). Moreover, the experimental results for the current profile, pressure profile and velocity profile have been presented.
\end{abstract}

\section{Introduction}

The climate change and fuel price both increase the stringent environmental policies have driven researchers to focus on finding technologies that are consistent with the environment, while the demand for electricity is forecasted to increase all over the world. One of the tools available to achieve the goal is to increase the share of renewable energy. Because of these commitments, the renewable energy industry is developing around the world and is one of the highest priorities of mankind. The new and renewable energy sources can guarantee a sustainable power production for the future energy needs [1,2].

Most of the climatic phenomenon that occurred worldwide in the last few years that can be accounted is the global warming. The multiannual temperature reports indicated that the temperature is constantly rising. There is a close correlation between the temperature rise

\footnotetext{
*Corresponding author: rashid@utp.edu.my
} 
and $\mathrm{CO}_{2}$ as well as the other gasses emissions. Many gases besides $\mathrm{CO}_{2}$ are accounted in different percentages for the greenhouse effect [3].

The free piston engine has a potential of minimizing of emission, as a result, more research has been undertaken in free piston engine to develop a more efficient system for vehicle propulsion and portable energy source application [2, 4]. The main problem concerning in electric vehicles is the performance of the batteries for the electric power storage system. Therefore, there are several solutions used to combine the power generated by the combustion engine and the electric motor inside a hybrid electric vehicle namely, parallel hybrid, series hybrid and parallel-series hybrid [3]. Notably, most of the systems use rotating generators and engines, therefore, linear electric generators connected directly to free piston engine is a viable solution. The vehicle traction is made by using two or four of electric motors mounted on the wheels. However, this system seems more complicated, but overall system efficiency is good [2,3].

The free-piston linear generator engine (FPLG) offers many advantages over its conventional rotary counterpart. These features include high power-to-weight ratio and multiple fuel capability as well as the high efficiency with low emissions. This is achievable because of its free-piston characteristics whereby during combustion the piston stays a shorter time at top dead center (TDC) than a conventional crank engine. This reduces heat loss and lowers the combustion temperature. When the linear engine is made as a platform to convert mechanical to electrical energy through a particular arrangement of a linear generator for portable power generators for commercial and domestic use $[4,5]$. Moreover, during the combustion stroke, the expansion of the free piston is faster compared with a conventional engine and the time spent around the TDC is shorter, meaning the speed is also higher around TDC [2, 3].

Figure 1 shows the cross-section of the major components of FPLG. This dual piston eliminates the need of a rebound device during functioning because the combustion stroke of one piston coincides with the compression stroke of the second piston. The external force that can be produced by the linear electrical machine needs to be utilized when the engine starts. The high vibration levels produced by such a system can be eliminated by using two or more systems that would work in anti-phase, requiring precise control [6-8]. This paper aims to design an appropriate linear generator for low grid power generation with low fuel. The idea is to use the TPMLG as the free-piston generator so that the mechanical energy can be directly converted to the electrical energy.

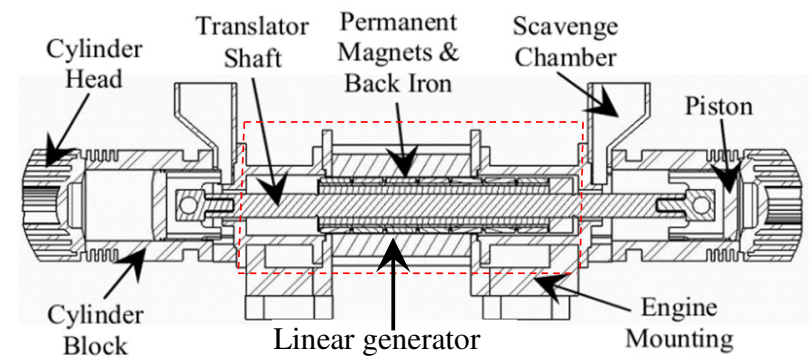

Fig. 1. Cross-section of the major components of free-piston linear generator engine [8]

\section{Design of the linear electric generator}

There are several linear electrical machines that could be used with a free piston engine, namely permanent magnet synchronous machines, permanent magnet variable reluctance machines, transverse flux machines, hybrid vernier machines, air-cored machines and moving coil machines. Each one of these technologies provide advantages and 
disadvantages that must be considered at the design stage, the moving coil structure has a light translator but uses sliding contacts or flexible connections that could reduce the system reliability, a moving magnet generator offers high air gap magnetic flux density and low moving mass but is sensitive to high temperatures near the combustion chambers and so on, and the air-cored structure eliminates most of the unwanted magnetic forces but requires a high magnetic flux densities to compensate the lack of the stator iron $[6,9]$.

In the selection of the linear generator for a free-piston engine power generation system, there are some aspects must be considered, namely the mover mass must be kept as low as possible because it has a negative influence on the entire mechanical system. Secondly, the proper insulation must be utilized to protect the permanent magnets because of very high temperature associated near the combustion chambers. Thirdly, rare-earth permanent magnets must be used to obtain high power densities that are resulting in a small size and easy way to place it inside the vehicle generating system. Lastly, for starting the internal combustion engine, the electrical machine must be able to work as a motor, thus the developed force must be high enough to compress the gas inside the cylinder for the first stroke.

However, the focus of this research is on a linear generator with permanent magnets that mounted on the moving part. The proposed design consists of a slotted core carrying six coils forming the stator part, and then another part is the moving part. The permanent magnets are quasi-Halbach magnetized are made of NdFeB. The shaft of the generator is made up of a nonmagnetic material, thus the leakage through that area is a magnetic field in the air gap.

When designing the generator some inputs were considered, such as rated power, rated voltage, rated efficiency, the linear velocity of a free piston engine, permanent magnet type, and others. Once the geometric dimensions of the linear generator were determined the structure was simulated using ANSYS, FEA based magnetic field computation software [8]. To reduce the simulation times only half of the generator was modeled and periodic boundary conditions were imposed. The optimal design of the linear generator used is a very important issue in the development of the entire power generation system. Based on Newton's second law of motion, the dynamic mechanical equation of linear generator is expressed as $[5,6]$

$$
\sum F_{x}=m a_{x}=m \frac{d^{2} z}{d t^{2}}
$$

where $m$ is the total mass of the moving part, including the shaft, pistons and magnets, and $a$ is the acceleration. During the starting the motion along a single axis only $(z)$, ignoring vibration along the other axes. Incorporating the mechanical forces above, therefore the following equation could be utilized to represent linear generator during starting for movement from TDC to BDC

$$
\begin{aligned}
m \frac{d^{2} z}{d t^{2}} & =F_{\text {mot }}+F_{\text {exp }}-F_{c o m p}-F_{c o g}-f \\
& =F_{m o t}(x)+F_{\text {exp }}(x)-F_{\text {comp }}(x)-F_{c o g}(x)-f
\end{aligned}
$$

Generally, the generators may be described by an equivalent electric circuit diagram, thus, can be simplified to $R L C$ circuit. Therefore, the voltage equation of the linear generator is written as [6]

$$
R i+L \frac{d i}{d t}+V=e
$$


From the Faraday's electromagnetic law, $e$ is expressed as

$$
e=-\frac{d \phi}{d t}
$$

By assuming that the flux-linkage is a function of $z$

$$
e=-\frac{d \phi}{d t}=-\frac{d \phi}{d z} \cdot \frac{d z}{d t}
$$

\section{Analysis model of the linear generator}

Based on the previous experiences and the given requirements a tubular permanent magnet linear generator (TPMLG) was designed for a low grid power generation. Then the field computation is performed by adopting a magnetic vector potential and a 2-D finite element analysis (FEA), thus, the electromagnetic performances of the proposed generator are simulated and analyzed.

Figure 2 shows the 3-D structure of the TPMLG and its main structure, that includes six coils and a mover consists of permanent magnet rings fixed on a linear shaft. The magnet topologies consist of quasi-Halbach magnetized PMs to create a magnetic flux path. Meanwhile, in the 2-D structure given in Figure 3 six coils are coupled together forming a single phase of the generator.

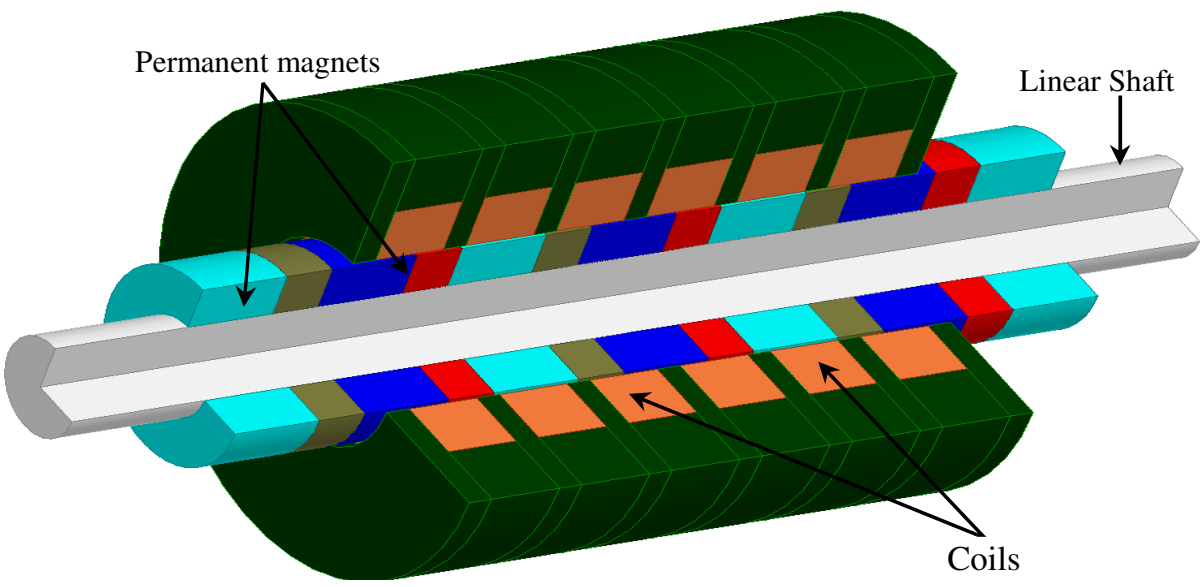

Fig. 2. The 3-D structure of the tubular permanent magnet linear generator

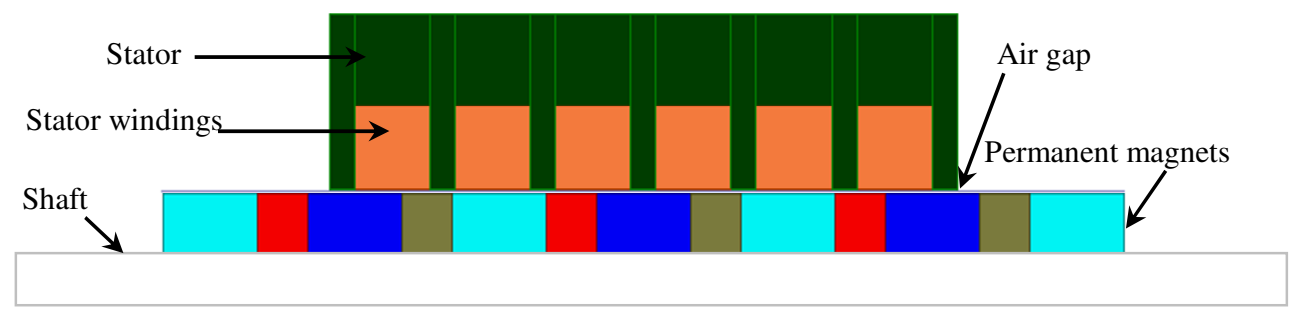

Fig. 3. The 2-D structure of the tubular permanent magnet linear generator

A 2-D axisymmetric finite element (FE) model of the generator was developed using commercial ANSYS software. The simulation results obtained are shown in Figure 4 is the 
magnetic flux plots in two positions of the mover, initial position and maximum stroke as shown in Figure 5. When the generator excited by the permanent magnets only, hence, to emphasize this statement, the shaded plot of the magnetic flux density distribution in the generator is presented in Figure 6, where high magnetic flux density values are noticed in the translator poles and stator teeth, while the average air gap magnetic flux density is $1.33 \mathrm{~T}$. As it can be observed the flux density values are very small in the other parts of the machine.

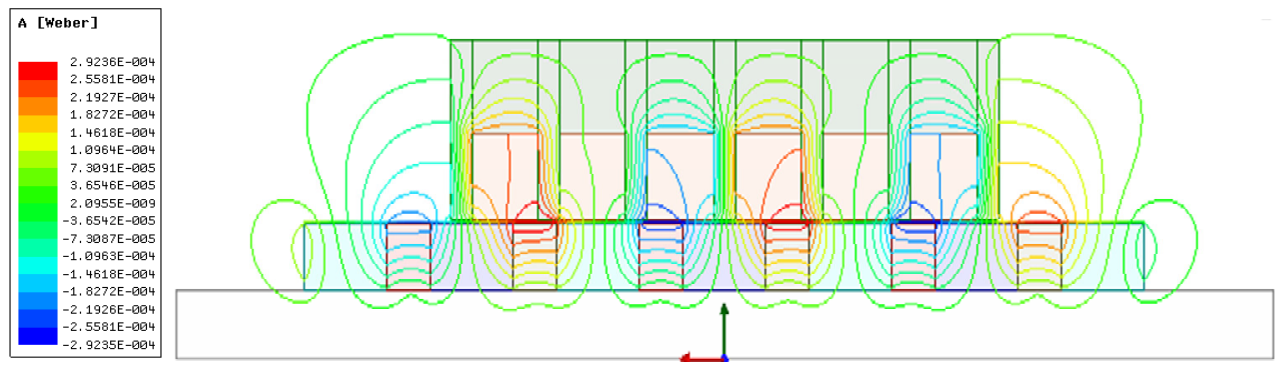

Fig. 4. The magnetic field lines obtained when the translator at the initial position

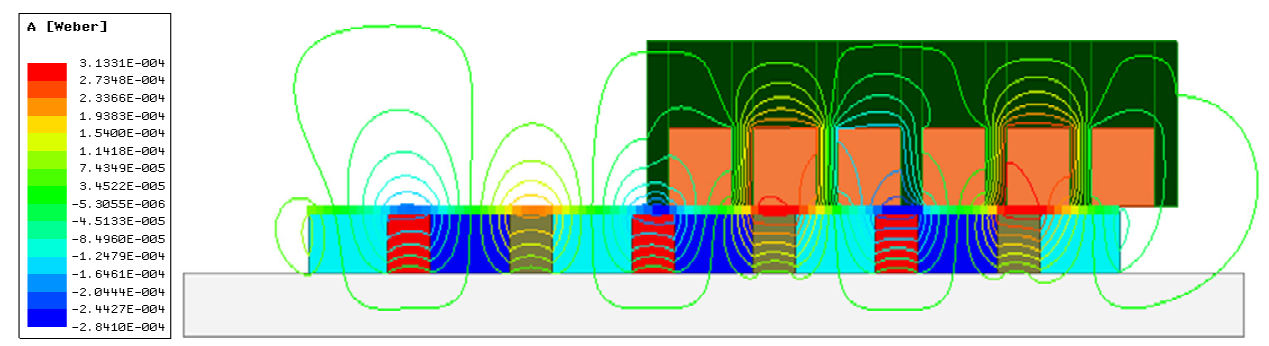

Fig. 5. The magnetic field lines obtained when the translator at the maximum stroke

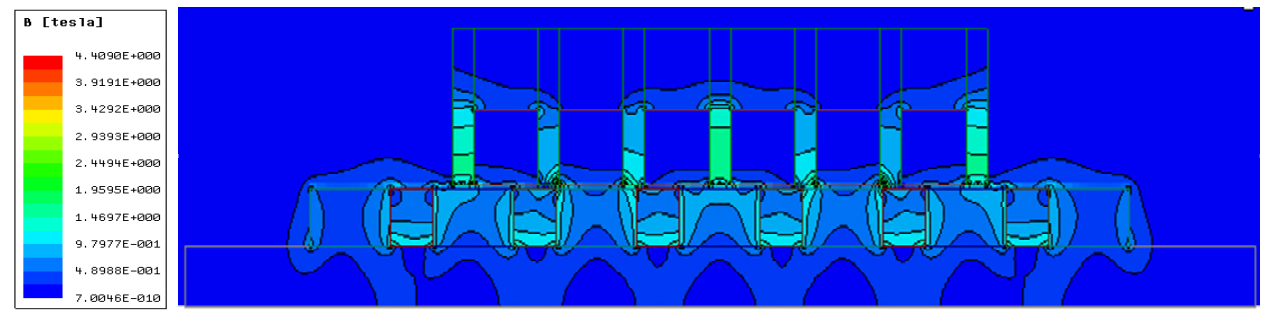

Fig. 6. The shaded plot of the magnetic flux density in the air-cored TPMLG

Figure 7 and Figure 8, respectively, show the distribution of magnetic flux and flux density produced by the PMs at the center of the air gap. The commercial software package ANSYS Maxwell is employed for non-linear 2-D FEA.

By moving the armature with the permanent magnets, a varying magnetic flux will pass through the windings, generating EMF. The main characteristics of the linear generator in this study were obtained by using FEA based numeric field computations, when the speed of the generator is constant. Therefore, for a dynamic simulation at the average constant linear speed of $6.0 \mathrm{~m} / \mathrm{s}$ the obtained flux-linkage is shown in Figure 9 is plotted together with flux-linkage of the iron-cored generator with short-dash as can be observed, the 
iron-cored generate higher flux-linkage than the ironless-cored. The induced no-load EMF and the winding inductance are shown in Figure 10 and Figure 11, respectively. As can be

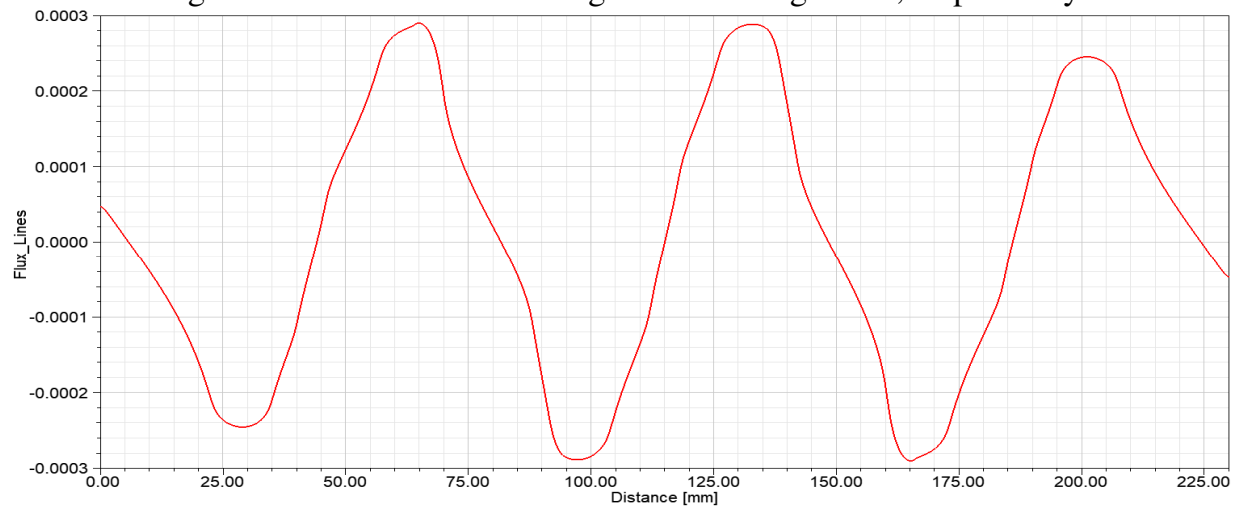

Fig. 7. Magnetic flux waveform of the air gap

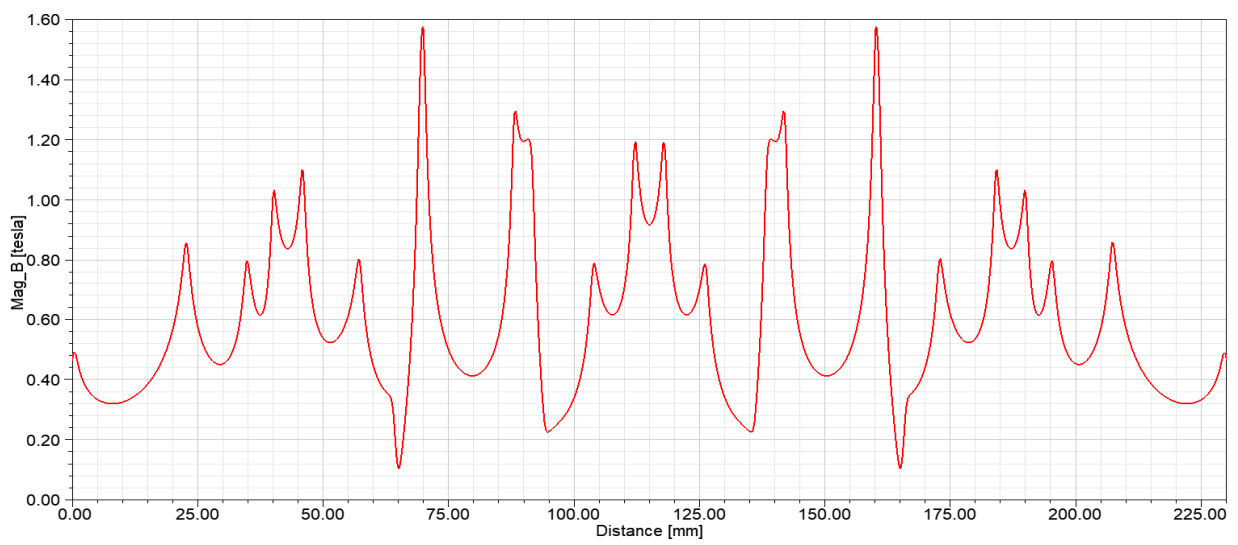

Fig. 8. Flux density waveform of the air gap

seen, also the iron-cord generator has a higher EMF and winding inductance and these indicate that it will posses higher power generation. For this type of linear generator, the effect that can be observed, only a small part of the magnetic flux generated by the magnets passes through the coil of the generator, hence EMF will be produced in its winding. 


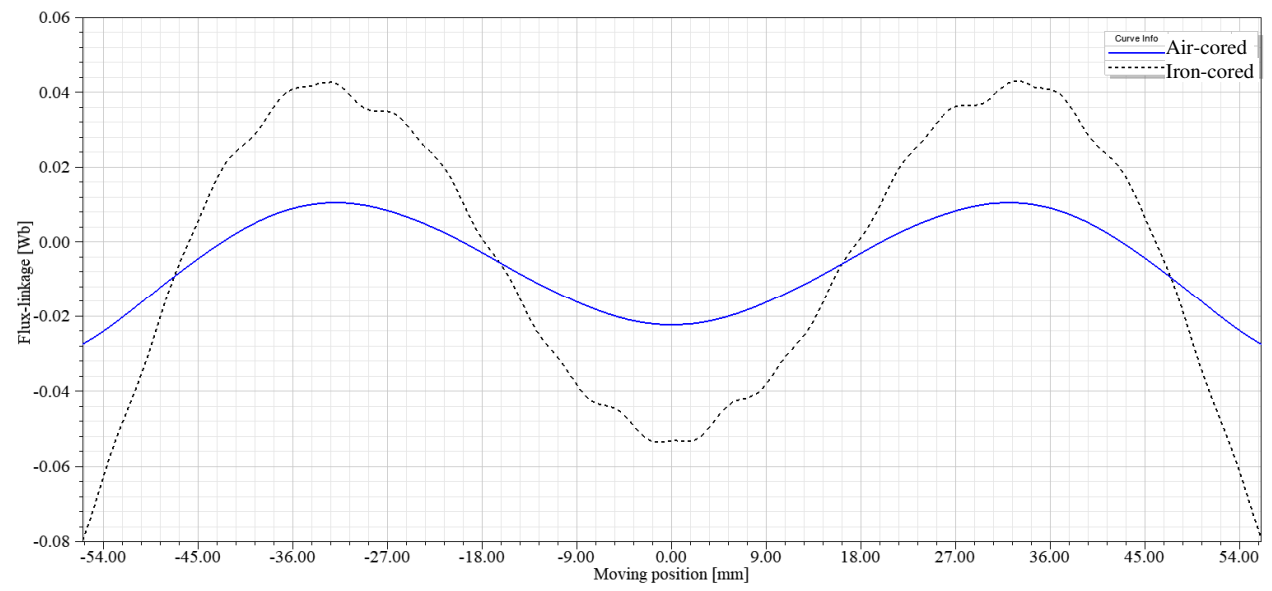

Fig. 9. Flux-linkage of air-cored and iron-cored TPMLG

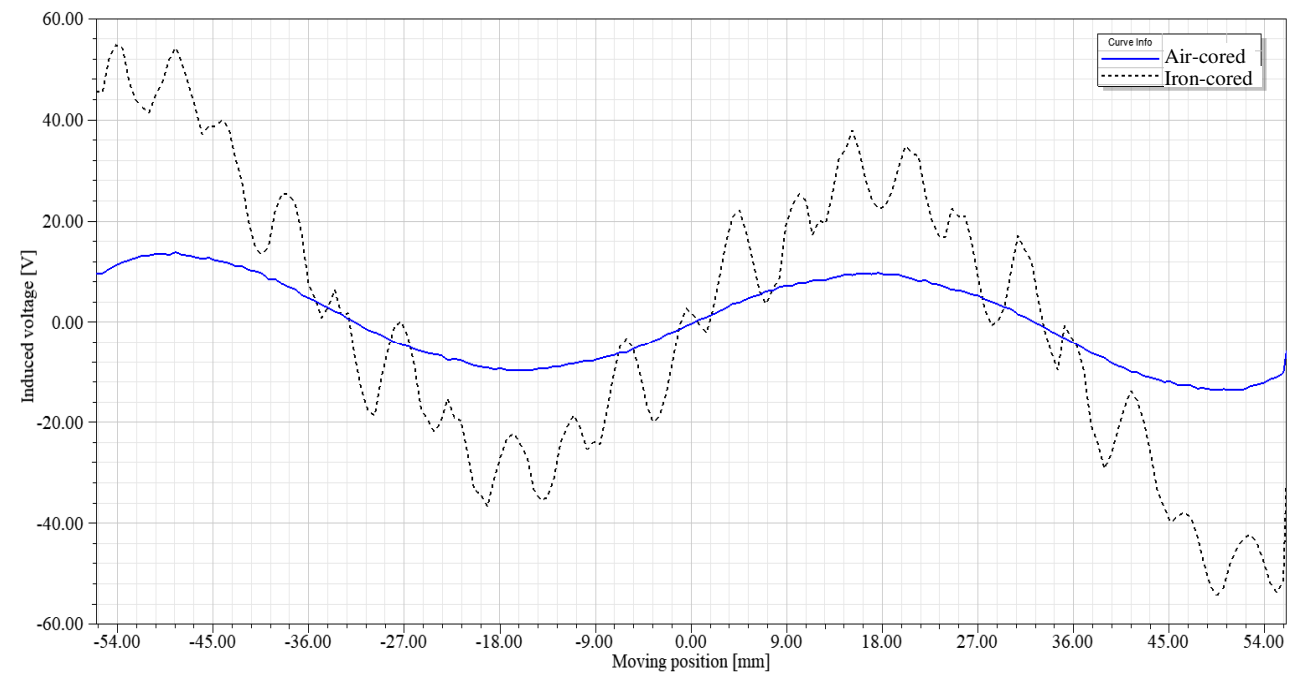

Fig. 10. Induced no-load EMF of air-cored and iron-cored TPMLG

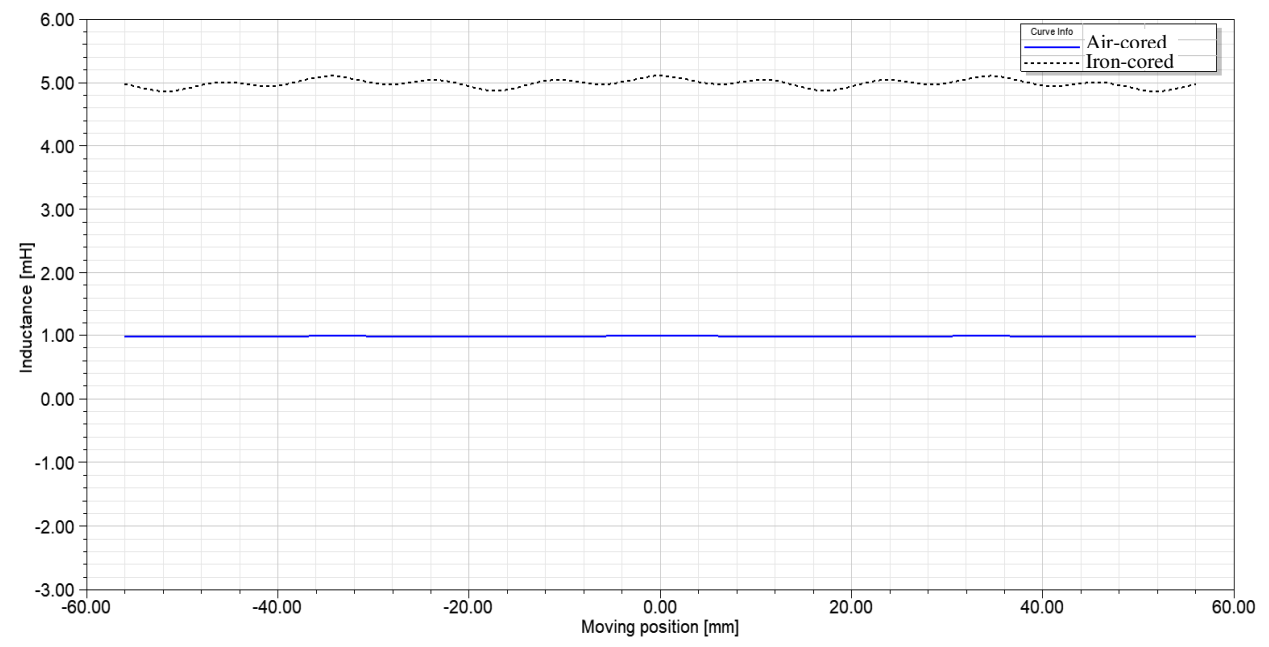


Fig. 11. Winding inductance of air-cored and iron-cored TPMLG

The thrust force provides power generation it resulted related to the translator positions when the PMs field acts in the direction of motion, whereas the interaction of PMs with stator produces an attractive force it called cogging force. Compared this force to the thrust force, this force is an order of magnitude lower. Finite element results for the proposed generator indicate that this force expressed as a stress and clearly justifies the investigation of air-cored machines in terms of simplified design and reduced mechanical structure as well as the minimization of the cogging force as clearly observed from Figure 12 the solid line is for air-cored TPMLG.

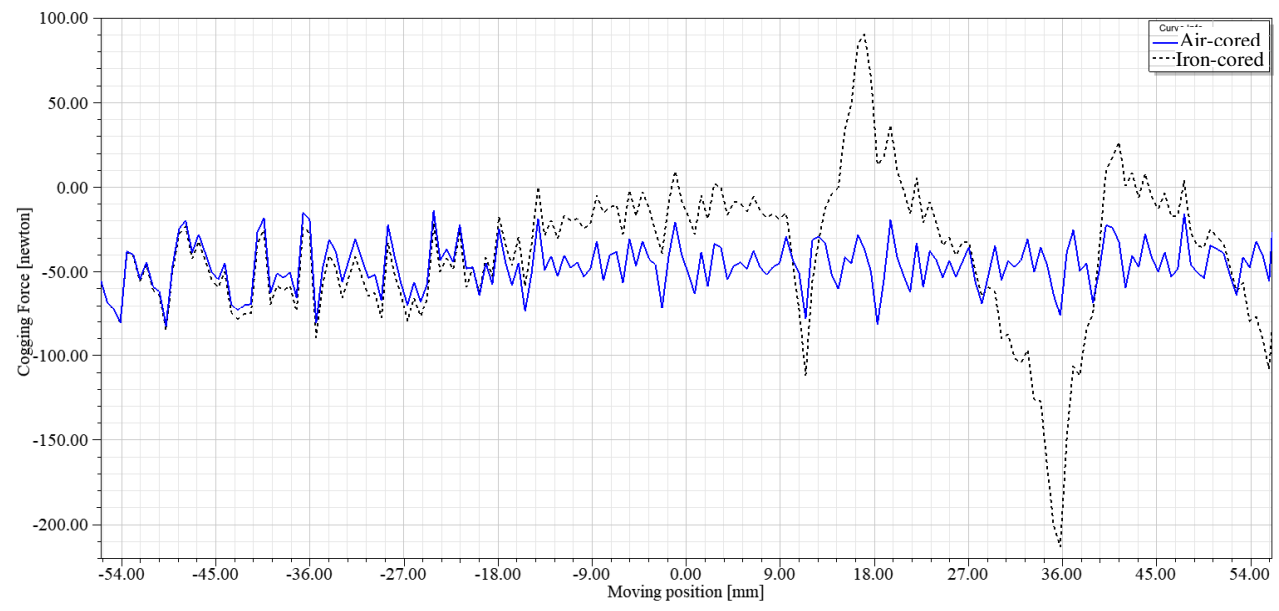

Fig. 12. The cogging force of air-cored and iron-cored TPMLG

The experiment was performed on a two-stroke, direct injection, and free-piston linear generator engine with two opposite combustion chambers as shown in Figure 13. The free-piston linear engine-generator (FPLG) involves a freely moving piston and a translator assembly between the two oppositely placed engine cylinders for combustion. The mover of FPLG is connected to the piston rods through flexible joints. This mover executes a reciprocating linear movement because of the gas pressure difference between the top of the two free pistons. The kinetic energy of the mover can be converted into electrical energy by the TPMLG. When the FPLG is an intake-expansion stroke, the piston moves from top dead center (TDC) to bottom dead center (BDC). The machine is operated as a brushless linear machine to produce the required motion. However, due to the very large peak compression force during the starting, thus, the limited current rating of stator coils and insufficient force have resulted in not possible to push the translator end to end in a single stroke. Hence, due to repeated compression-expansion of the engine cylinders and constant application of motoring force in the direction of natural bouncing motion, the amplitude and speed of the translator are expected to grow due to mechanical resonance. 


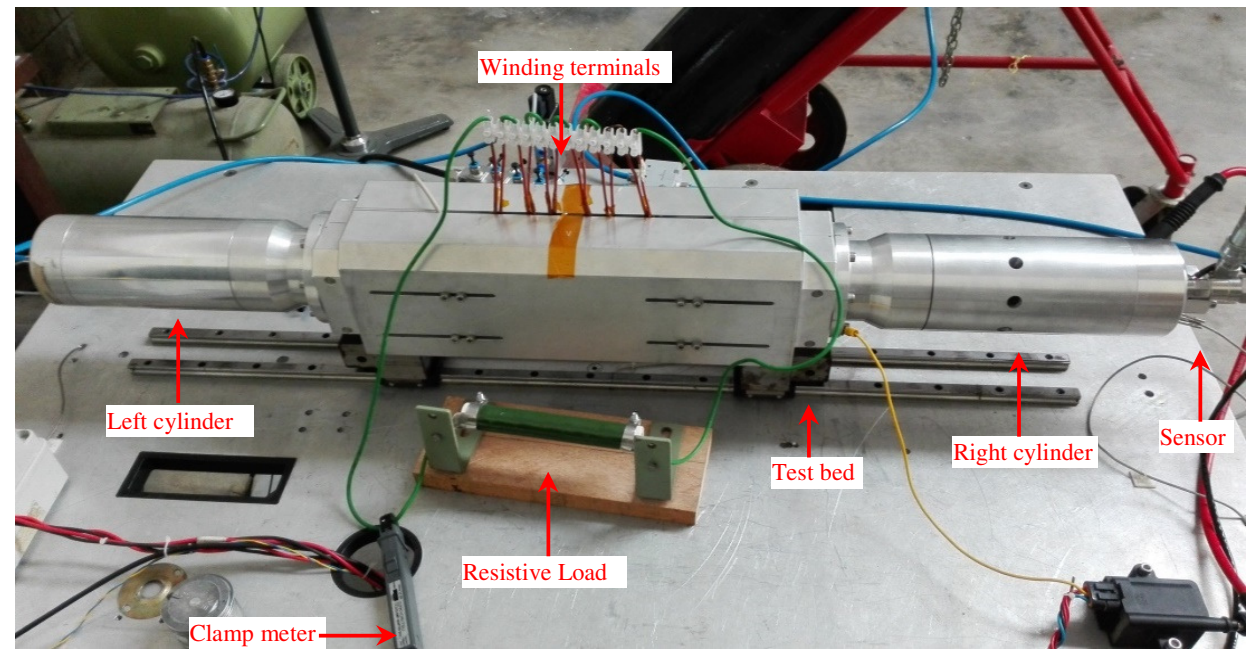

Fig. 13. Prototype of free-piston linear generator engine on the test bed

The TPMLG is the energy generation device in the FPLG, and thus, its appropriate selection at the conceptual design stage is crucial [3]. The Free piston internal combustion engines offer better dynamic profiles and can work at variable compressed ratio as well as has a less pollution. Figure 14 (a) and (b) shows pressure versus displacement of the left and right cylinder of the engine. It shows that the pressure in the left and right cylinder are not equal in both configurations. This can be attributed to the fact that there is a leakage in the left cylinder. The maximum pressure is observed in the left and right cylinders. Furthermore, the investigation showed that the compression profile is higher than the expansion profile. Hence, the region under the curve is a negative work due to the work was done by motoring force applied to the piston. This shows that the energy is supplied to the engine rather than extracting from it. Figure 15 shows the current profile versus time, whereas Figure 16 shows the current profile versus displacement, as can be observed, the maximum current obtained is around $9.0 \mathrm{~A}$.

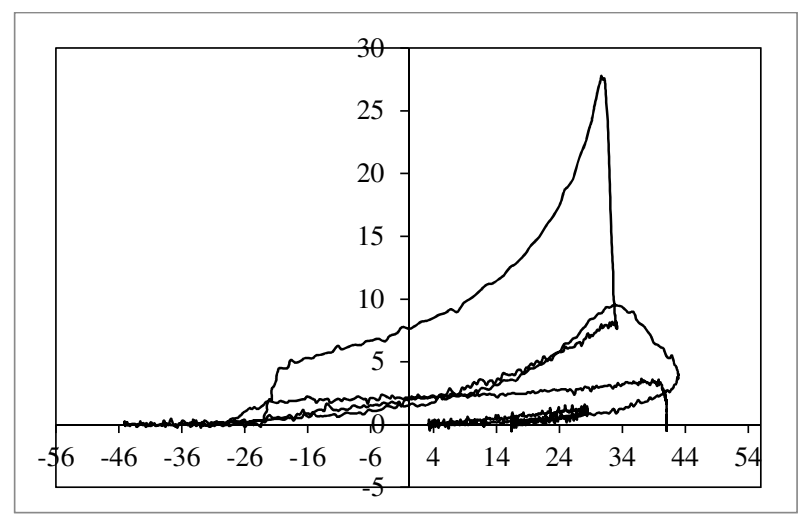

(a) In-cylinder pressure 1 


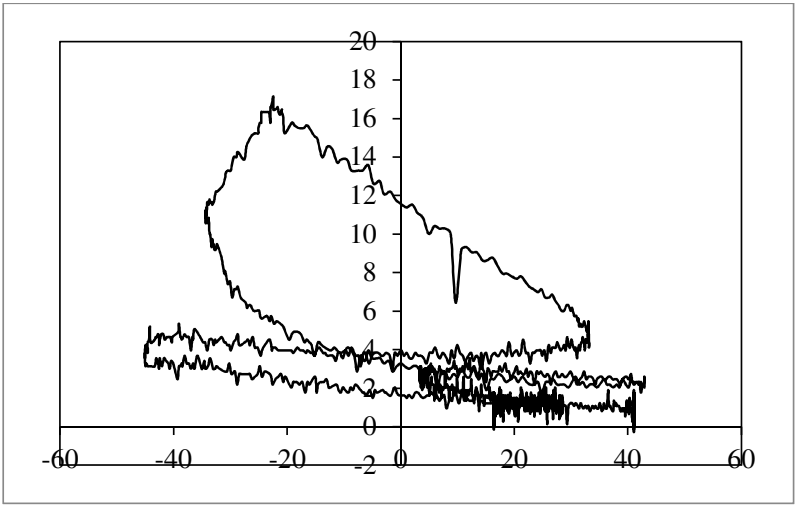

(b) In-cylinder pressure 2

Fig. 14. Engine compression pressure versus axial displacement

When the piston speed falls below the cut-off speed, power generation is stopped so reducing the electrical braking on the translator. At this speed, the voltage generated by the linear generator will be higher. Figure 17 shows the cut-off speed, the high speed will increase the compression ratio while lower speed will reduce it. The highest recorded piston velocity at $6.0 \mathrm{~m} / \mathrm{s}$, followed by $2.0 \mathrm{~m} / \mathrm{s}$. The velocity profile at both ends represents an expansion and compression profile whereby piston velocity decrees towards the end because of resistance during compression stroke and change of direction.

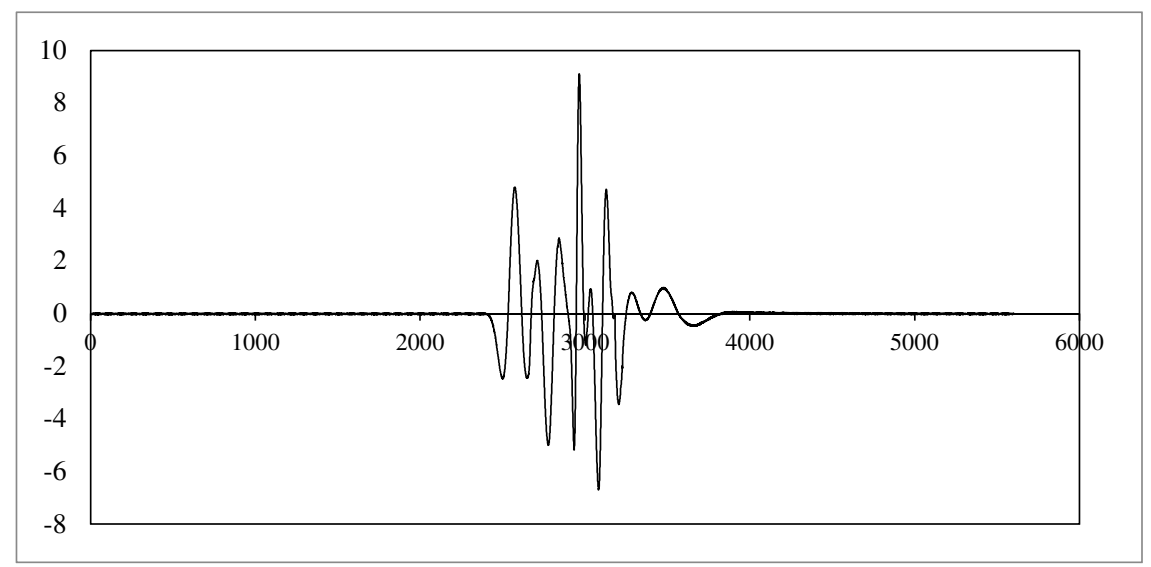

Fig. 15. Current profile versus time 


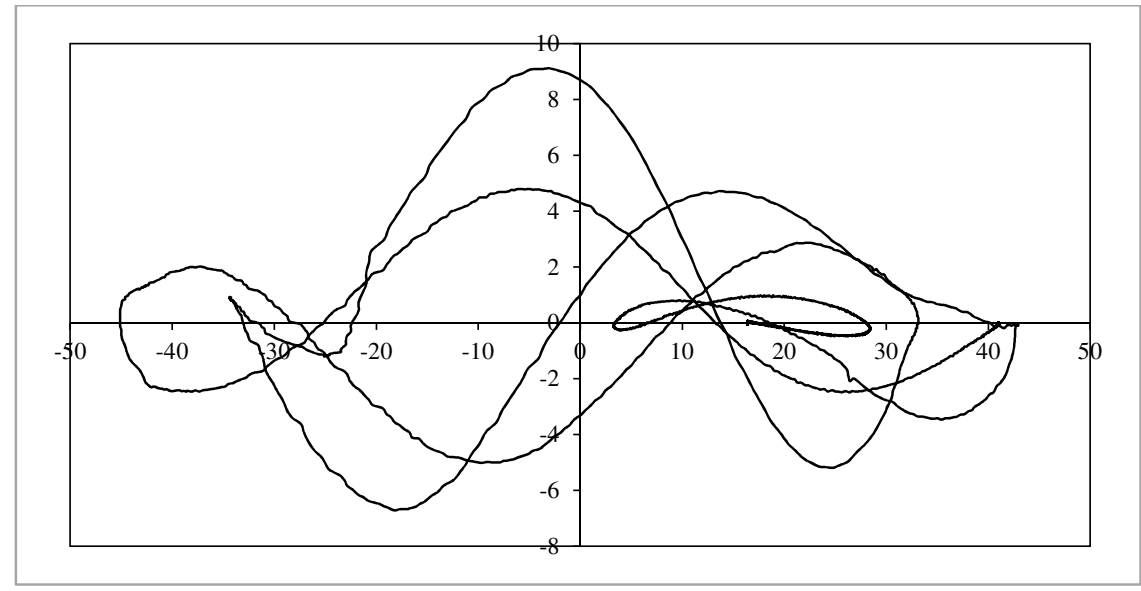

Fig. 16. Variation of current against displacement of the translator

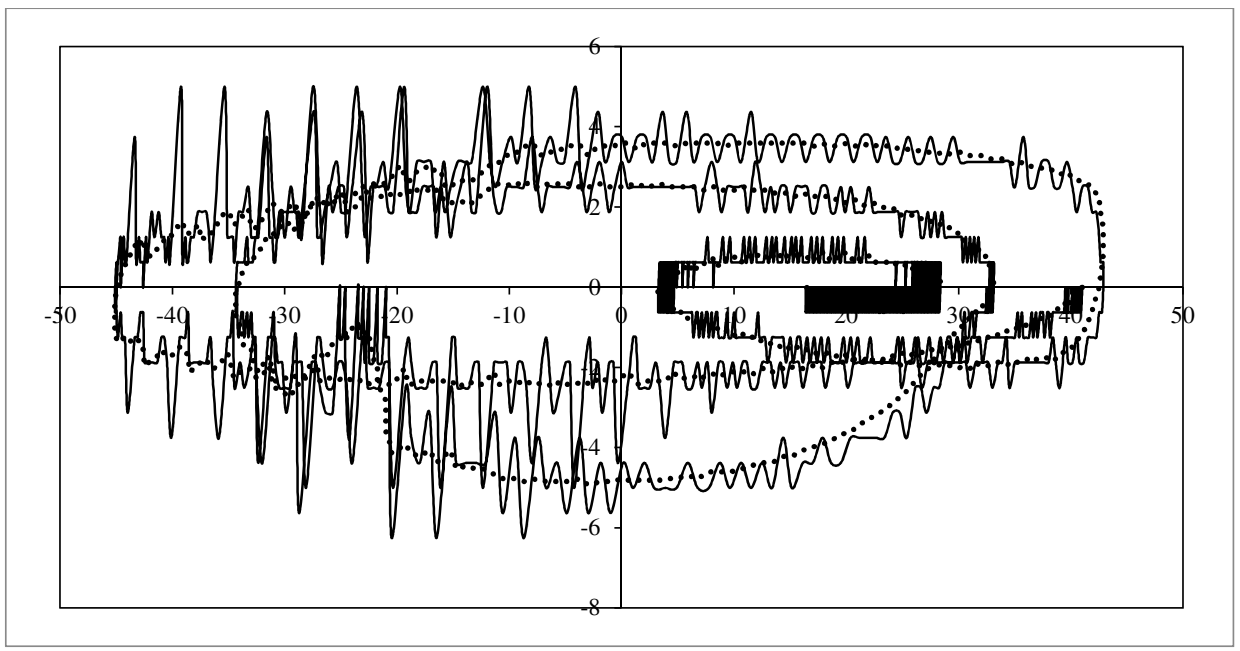

Fig. 17. Piston dynamics of a free-piston engine, piston velocity profiles versus displacement

\section{Conclusion}

The use of electric linear generators driven by internal combustion free piston engines offers better performance compared to conventional systems for clean energy converters. However, a tubular permanent magnet linear generator (TPMLG) for low grid power generation has been proposed and analyzed. This kind of linear generators has superior performance, nevertheless, it has a problem of high magnetic attraction force between the permanent magnets and the magnetic stator teeth. However, to eliminate this attraction force, this paper presents the design and analysis of ironless-stator single-phase TPMLG. It waives the use of any steel in a stator, therefore, the attraction force between the moving and stator part can be minimized as much as it is possible. The ironless-stator TPMLG has a low cogging force, despite, its power density is low. The magnetic field computation of the proposed generator was performed by applying a magnetic vector potential and a 2-D finite element analysis (FEA) and also some experimental results have been presented. 
Authors gratefully would like to thank Yayasan Universiti Teknologi PETRONAS (UTP) (0153AA-A92) and the Petroleum Research Fund (0153AB-A34) for funding this research work.

\section{References}

1. L. Szabo and C. Oprea. Oradea University Annals pp. 120-125 (2006)

2. B. Jia, R. Mikalsen, A. Smallbone, Z. Zuo, H. Feng, and A. P. Roskilly. App. En., 179, pp. 1166-1175 (2016)

3. J. Chen, Y. Liao, C. Zhang, and Z. Jiang. Design and ananysis of a permanent magnet linear generator for a free-piston energy converter. IEEE $9^{\text {th }}$ Conference on Industrial Electronics and Applications, pp. 1719-1723 (2014)

4. Z. A. Ezrann Z., A. I. Abdulwehab, A. A. A. Rashid, Saiful A., and Zulkifli. J. of Mech. Eng. and Sci., 8, pp. 1393-1400 (2015)

5. S. A. Zulkifli, M. N. Karsiti, and A. R. A. Aziz. Starting of a free-piston linear enginegenerator by mechanical resonance and rectangular current commutation, IEEE Vehicle Power and Propulsion Conference, pp. 1-7 (2008)

6. H. Feng, Y. Song, Z. Zuo, J. Shang, Y. Wang, and A. P. Roskilly Energies 8, pp. 765785 (2015)

7. C. Oprea, L. Szabó, and C. Marţiş, Linear Permanent Magnet Electric Generator for Free Piston Engine Applications, $X X^{\text {th }}$ International Conference on Electrical Machines, pp. 691-696 (2012)

8. A. E. Z. B. Zainal. Int. J. of Aut. Eng. 4, pp. 47-53 (2013)

9. I. I. Abdalla, T. Ibrahim, and N. B. M. Nor. Int. J. of Elec. Power \& Energy Sys. 77, pp. 263-270 (2016) 